\title{
NICOS POULANTZAS E O DIREITO: ENTRE PACHUKANIS E STUCHKA
}

\section{Thiago Barison $^{1}$}

\section{Resumo:}

Este ensaio compara, de um lado, dois textos de Nicos Poulantzas em que defende diferentes concepções sobre o Estado capitalista com, de outro, dois autores marxistas fundamentais para a compreensão do que é o direito. A obra Poder Político e Classes Sociais faz uma análise estrutural do Estado que o põe em relação com as condições de reprodução do modo de produção capitalista, ao que corresponde a formulação de Pachukanis sobre a forma jurídica e a forma mercantil. Na obra Estado, Poder e Socialismo, Poulantzas introduz mudanças que podem aproximá-lo à concepção normativista de Stuchka, no qual o Estado e o direito são pensados a partir do poder de classe.

Palavras-chave: Estado capitalista; forma jurídica e forma mercantil; materialidade estatal e correlação de forças; normativismo marxista.

\section{INTRODUÇÃO}

Nicos Poulantzas tem duas fases em sua teoria do político, dentro do qual localiza o direito, no Modo de Produção Capitalista (MPC). Na obra Poder Político e Classes Sociais (PPCS), de 1968, faz uma análise em três séries de determinações: estruturas, em que são cotejadas as relações entre as instâncias do MPC; instituições ou aparelhos, onde se materializam as estruturas e onde se organizam as práticas da dominação; e práticas ou a luta de classes. E em seu último livro, Estado, Poder e Socialismo (EPS), de 1978, Poulantzas introduz uma novidade: o Estado é pensado como uma "condensação de uma relação de forças" entre as classes em luta. O objetivo deste ensaio é relacionar essas duas fases com duas teorias canônicas, por assim dizer, do direito para o materialismo-histórico: a crítica do direito enquanto forma jurídica, de E. B. Pachukanis, e o normativismo marxista, de P. Stuchka².

1 Doutorando em Direito do Trabalho e Seguridade Social pela Faculdade de Direito da USP. E-mail: thiago.barison@gmail.com.

2 Poulantzas, Nicos. Poder político e classes sociais. Trad. Francisco Silva; Rev. Carlos R. F. Nogueira. São Paulo: Martins Fontes, 1977.

Estado, poder e socialismo. 4a ed. Trad. Rita Lima. São Paulo: Paz e Terra, 2000, (1a ed., 1978). PASUKANIS, E. B. Teoria geral do direito e o marxismo. Trad. Paulo Bessa. Rio de Janeiro: Renovar, 1989. STUCHKA, P. I. "The Revolutionary Part Played by Law and the State - A General Doctrine of Law”. In: HaZARD, John N. (org.). Soviet Legal Philosophy. Cambridge: Harvard University Press, 1951, pp. 17-69. Sobre a periodização da obra poulantziana, cf. CoDATO, Adriano. 
Nessa comparação sumária, daremos maior importância às teses lançadas em $P P C S$, que constituem a base do edifício teórico poulantziano. Conforme se verá, a introdução das novidades em EPS não se faz sem antagonismos com as bases desse edifício. Todavia, são exatamente as inconsistências daí advindas que permitem se vislumbrar os pontos obscuros do sistema teórico e que necessitam de um processo de retificação. O direito, enquanto estrutura e enquanto parte das instituições estatais, está no cerne dessas fissuras e das possibilidades de superação crítica.

\section{A TEORIA DO ESTADO E DO DIREITO NO MODO DE PRODUÇÃO CAPITALISTA}

Em PPCS, podemos, após um trabalho teórico de retificação, valorização e de interpretação, conceber a estrutura do Estado capitalista para Poulantzas em consonância com a teoria pachukaniana da forma jurídica ${ }^{3}$. Décio Saes interpreta a definição poulantziana da "superestrutura jurídico-política" do capitalismo por seus efeitos ideológicos, a saber, de "isolamento/individualização" dos agentes da produção e de "representação de unidade do "povo nação", produzidos pelo direito burguês e pelo burocratismo ${ }^{4}$. Essa estrutura jurídico-política é funcional à estrutura econômica capitalista, ao trabalho assalariado, à circulação mercantil e sua garantia pela violência organizada num complexo institucional terceiro em relação aos agentes individualizados do processo econômico.

A totalidade do MPC, tal como determinada em última instância pelo nível econômico, é dizer, pela relação fundamental entre o produtor direto e os meios de produção, articula uma separação entre as regiões da prática social, entre a economia e a política: não sendo o sobre produto extorquido pela força, ante a separação dos produtores diretos da posse dos meios de produção, a esfera propriamente política e a violência nela contida são separadas das relações econômicas. A isso corresponde no Estado capitalista, por sua vez, a separação entre esferas pública e privada, entre o que Gramsci chama de sociedade civil e sociedade política 5 .

Mas Poulantzas insiste em precisar: na sociedade civil não existam indivíduos verdadeiramente isolados, o processo de produção é coletivo. Mas os agentes da produção vivem ideologicamente isolados e individualizados. É a essa contradição, entre, de um lado, a esfera da produção coletiva e, de outro, a esfera da circulação mercantil e das relações jurídicas, que corresponde o efeito ideológico de representação da unidade

"Poulantzas, o Estado e a revolução. In: Revista Crítica Marxista. São Paulo, n. 27, 2008, pp. 65-85, bem como JeSSOP, Bob. Nicos Poulantzas: Marxist Theory and Polítical Strategy. London: Macmillan, 1985.

${ }^{3}$ Apresentamos os resultados a que chegamos nessa empreitada em Nicos Poulantzas e o direito: um estudo de Poder político e classes sociais. Dissertação de mestrado. São Paulo: Faculdade de Direito/Universidade de São Paulo, 2010.

${ }^{4}$ SAES, Décio. "A questão da autonomia relativa do Estado em Poulantzas". In: Revista Crítica Marxista. Rio de Janeiro: Xamã, n. 7, 1998a, pp. 46-66.

${ }^{5}$ GramsCI, Antonio. Cadernos do Cárcere v. 3 - Maquiavel: notas sobre o Estado e a Política. Trad. Carlos Nelson Coutinho. Rio de Janeiro: Civilização Brasileira, 2000. 
do todo, a cargo do Estado e para isso organizado burocraticamente: um corpo especializado, impessoal e não identificado com as classes - como de resto o conjunto das instituições, nas quais as determinações de classe ficam sistematicamente ausentes. $O$ burocratismo contribui para essa representação de unidade à medida que apresenta os postos de exercício da política como abertos à ocupação por qualquer cidadão, independentemente de sua condição de classe. Assim, direito burguês e burocratismo, isolando e unificando, constituem as estruturas ou as formas políticas do capitalismo.

Poulantzas destaca, ainda, que os efeitos de isolamento e individualização produzidos pelo direito burguês e por sua outra face que é o mercado fazem com que a burguesia seja incapaz de se auto organizar politicamente para exercer a dominação política. A separação entre economia e política no capitalismo gera efeitos sobre essas esferas de atuação na própria classe burguesa. A burguesia, isolada e em luta constante no mercado - a anarquia da produção - incide num economicamente atávico, um "egoísmo de fração" no plano político. A dominação no capitalismo é distinta daquela que há nos modos de produção anteriores. Poulantzas defende a originalidade da dominação hegemônica de classe.

Vejamos, pois, sinteticamente as determinações do aparato de Estado e das lutas de classes. Para Nicos Poulantzas, as estruturas informam, organizam e ao mesmo tempo se materializam nos aparelhos ou instituições - no limite, as estruturas, num só e mesmo movimento, enquadram as práticas e materializam-se nelas. Os aparelhos são recursos materiais e ideologias que organizam e reproduzem as práticas sociais. $\mathrm{Na}$ divisão social do trabalho pensada em sentido amplo - não só economicamente, mas materialmente - o Estado e o funcionamento de suas instituições são os lugares privilegiados das práticas políticas, de direção, organização, comando, representação e de exercício - também organizado "industrialmente" - da violência. Assim, o judiciário, o exército, a diplomacia, os "Poderes" executivo e legislativo, o idioma nacional, os meios de comunicação de massa, as empresas e os serviços públicos, enfim, todas as instituições sob o capitalismo são organizadas pelo estrutura do direito burguês e do burocratismo - e ao mesmo tempo as materializam -, contribuindo para a função do Estado: a coesão de uma formação social, em geral, e, em particular, a organização da dominação hegemônica de classe - paralela à desorganização das classes dominadas.

Mas, então, o Estado é um "sujeito"? Poulantzas evita a todo tempo essa imagem que reputa um desvio. No entanto, é acusado de "estruturalismo" ou "formalismo", como no debate com Ralph Miliband'. Vejamos, agora, como na teoria contida em $P P C S$ o Estado cumpre com essas funções de coesão social e organização da hegemonia, e como Poulantzas responde à crítica de formalismo, no qual as estruturas substituiriam as classes enquanto sujeitos da história.

${ }^{6}$ Miliband, Raph. "Poulantzas and the Capitalist State". In: New Left Review, n. 82, 1973, pp. 83-92. 
Segundo nossa interpretação de tal obra de Poulantzas, um tanto embasada nos comentadores e outro tanto livre, passa-se que o aparato de Estado recebe, num processo contraditório, as pressões dos interesses das diversas classes e frações em luta, que atravessam todo o complexo de aparelhos estatais, agências executivas e instituições representativas. Esse processo permite que os representantes políticos e o pessoal de Estado, é dizer, não só os mandatários mas a esfera política em sentido mais amplo, produzam, em sua interação, a formação e superação constantes de equilíbrios instáveis de compromissos no seio do bloco de classes e frações de classes no poder. Os limites e a dinâmica desses arranjos de compromissos e interesses são postos na relação com o conjunto das classes dominadas e na relação com os blocos no poder das demais formações sociais da cadeia imperialista, de tal sorte que tais arranjos e as posições no interior dos diferentes blocos no poder são decifráveis na política econômica, social e exterior do Estado em cada momento — eis aí a agenda de pesquisa concreta poulantziana.

No entanto, a despeito desse fracionamento e dessa dinâmica conflitual determinada por múltiplas forças, bem como da apropriação diferencial de instituições, como, recentemente no Brasil, por exemplo, o Banco Central pelo grande capital financeiro internacional e o BNDES pela grande burguesia interna brasileira, a dominação política no capitalismo é sempre exercida unitariamente pelo bloco no poder sobre as classes dominadas. Ou seja, a diversidade das instituições estatais e as diferentes presenças das frações e classes nelas não implicam a "repartição" do poder em pedaços. O poder, para Poulantzas, é exatamente essa relação entre o bloco de classes dominantes e as classes dominadas.

Essa pressão das diversas classes e frações de classes se dá por organizações de interesses, associações, institutos, partidos, correntes de opinião, jornais etc. Ou podem essas pressões serem até mesmo "percebidas" pelos representantes políticos e pelas demais forças atuantes - como no caso das classes-apoio, que não se organizam mas que são representadas? ${ }^{7}$ Essa "percepção", que importa nas relações de forças entre as classes em conflito, é chamada por Poulantzas de "efeito pertinente", a ser buscado em concreto, em cada conjuntura. Numa democracia, mesmo os representantes-mandatários políticos se comportam também com relativa autonomia, ainda que menor: esse comportamento opaco é induzido pelo próprio funcionamento das instituições estatais. A “cena política”, que oculta, dissimula e representa (e também organiza) os interesses de classes é o corolário da autonomia relativa do aparelho de Estado ${ }^{8}$. Os representantes podem mesmo ignorar

\footnotetext{
${ }^{7}$ É o caso dos camponeses parcelares, representados por Luís Bonaparte, na França de 1848-52. Cf. PoulanTZAS, Nicos. Poder político e classes sociais. op. cit., pp. 81-94.

${ }^{8}$ Cf. BOITO JR, Armando. Estado, política e classes sociais - ensaios teóricos e históricos. São Paulo: Unesp, 2007, cap. 6, "Cena política e interesses de classe na sociedade capitalista: a análise de Marx”, pp. 137-151. 
que representam interesses e a burocracia civil e militar pode se achar acima das classes. Mas tanto uns como outros servem a interesses de classe e à construção da hegemonia? .

Em nossa narrativa o aparato de Estado seguiu sendo o "sujeito". Expliquemo-nos: trata-se de um processo contraditório de pressão dos interesses imediatos e conflitantes entre si das classes e frações dominantes, nos quadros postos pela relação mais ampla entre os dominantes com as classes dominadas; um processo que é o próprio sujeito - para utilizarmos uma expressão cara a Althusser ${ }^{10}$. A estrutura do Estado capitalista enseja um processo contraditório entre as classes e frações em luta que funciona como organizador da hegemonia burguesa.

Assim, a revolução proletária, em PPCS, pressupõe a crise dessa hegemonia e a destruição dos aparelhos de Estado, tendo como última fronteira a força organizada. Uma nova estrutura jurídico-política seria o ponto de apoio para a modificação da divisão social do trabalho. Em uma palavra: o ponto de apoio estrutural para o longo processo de transição a uma nova totalidade macroestrutural, com novas relações econômicas derivadas dessa nova forma política, que prepara a sua própria extinção, na formulação clássica do marxismo ${ }^{11}$.

Portanto, a perspectiva estrutural supera a problemática do sujeito. As relações capitalistas de produção, que prescindem da força e da dependência pessoal em sua reprodução normal, põem não só uma forma anárquica de organização da produção e das trocas, senão que estabelece igualmente, no plano político, um correspondente padrão de luta de classes, mais complexo, indireto e relativamente mais distante da esfera de ação, vontade, consciência ou mesmo interesse direto das classes dominantes, em comparação com os modos de produção anteriores.

O momento relacional da teoria do político de PPCS aparece mais claramente na resposta à pergunta de Miliband, que a julga demolidora do esquema que condena: quão relativa é essa autonomia? E o que a determina?

Se a auto-organização política e ideológica burguesa, sua coesão com as outras frações e classes no bloco no poder e a conjuntura econômica lhe forem favoráveis - pensemos -, menor tende a ser a autonomia do aparelho de Estado e mais condições tende a ter a burguesia para impor uma política social e econômica estatal que atenda seus interesses mais diretamente. A conjuntura neoliberal dos anos 1990 é um exemplo

\footnotetext{
${ }^{9}$ PoulantZAS, Nicos. “The Capitalist State - Reply to Miliband and Laclau”. In: New Left Review, n. 96, 1976b, pp. $63-83$.

${ }^{10}$ Althusser, Louis. “A Querela do Humanismo I”. In: Revista Crítica Marxista. São Paulo: Editora Xamã, n. 9, 1999, pp.9-51.

${ }^{11}$ BALIBAR, Étienne. "Elementos para una teoría del tránsito”. In: ALTHUSSER, Louis; Para Leer el Capital. $4^{a}$ ed. Trad. Marta Harnecker. Mexico: Siglo Ventiuno Editores, 1970, pp. 297-335. Cf. NAVES, Márcio Bilharinho. Marx: ciência e revolução. São Paulo: Quartier Latin, 2008. Lênin, V. I. O Estado e a Revolução. São Paulo: Expressão Popular, 2007. Sobre o conceito de forma política, cf. MASCARO, Alysson Leandro. Estado e Forma Política. São Paulo: Boitempo, 2013.
} 
disto: a ofensiva burguesa logrou submeter de uma maneira nova o aparato de Estado a seu serviço direto. O banco central se tornou no Brasil uma instituição "autônoma" frente à política e totalmente vinculada aos interesses da finança. As privatizações atendiam interesses os mais imediatistas. É claro que tudo isso encontra e encontrou efetivamente no exemplo brasileiro limites, à exata medida das possíveis contradições entre os dominantes e, fundamentalmente, da pressão das classes dominadas.

Agora numa conjuntura de crise, de equilíbrio de forças no interior do bloco no poder e de pressão dos dominados que obstaculize compromissos como os anteriores, nesta outra hipótese, à exata medida da fragilidade das classes e frações dominantes em sua auto-organização hegemônica é que o aparato de Estado tende a adquirir maior autonomia - maior, mas ainda relativa - , podendo impor sacrifícios aos interesses imediatos dos dominantes, atender interesses também imediatos dos dominados e assegurar os interesses políticos de longo alcance da burguesia. O exemplo clássico é o do bonapartismo, segundo o tratamento que Karl Marx dá em Dezoito Brumário de Luís Bonaparte à conjuntura francesa de 1848-52 $2^{12}$. Pode parecer que uma ditadura militar nada tenha que ver com as pressões e a força das classes dominadas, ou com a imposição de sacrifícios a setores dos dominantes. Esse é um esquema geral que evidentemente não substitui, ao contrário permite e instrumentaliza, as análises "concretas das situações concretas". Uma ditadura como a chilena ou a brasileira não deixa, contudo, de ser a ação direta de um setor do Estado - as forças armadas - para resolver uma crise no lugar das organizações e representantes políticos da burguesia e das demais classes e frações, mas em favor dela, ainda que puramente através da violência sobre os dominados. Isto não deixa de ser, contudo, uma aposta alta, eis que significa o acionamento do "último recurso" que, se vencido pelas classes dominadas, a partir de um exército popular (Cuba e Nicarágua) ou de uma quebra no exército burguês entre "legalistas" e "golpistas" (um brevíssimo momento no Chile, após o "tancazo"), ingressa-se no terreno da revolução ${ }^{13}$. Com efeito, a violência e o momento militar, em articulação com a correlação internacional de forças, constituem a última fronteira do poder político.

Fizemos aqui uma síntese, que pretende apenas passar pelas teses que, em PPCS, desenvolvidas que estão amiúde, fazem dessa obra talvez o principal esforço de sistematização dos clássicos do materialismohistórico sobre a política. Conceitos que operam nas análises de conjuntura do movimento operário e socialista são identificados, delimitados e organizados num instrumental teórico coerente.

E, embora Poulantzas se volte para o Estado capitalista, não deixa por isso de se conectar à mais avançada teoria crítica do direito: a teoria pachukaniana, na qual a forma jurídica tem por fundamento a forma

\footnotetext{
${ }^{12}$ MARX, Karl. "O 18 Brumário de Luís Bonaparte”. In: IASI, Mauro. (org.). A revolução antes da revolução II - Karl Marx. São Paulo: Expressão Popular, 2008 (coleção “Assim lutam os povos”), pp. 199-337.

${ }^{13}$ Apoiamo-nos aqui na análise de HandaL, Jorge Shafik. El Poder, el Carácter y la Vía de la Revolución y la Unidad de la Izquierda. El Salvador: 1981. Disponível em: “http://www.marxists.org/espanol/handal/1981/001.htm”, acesso em set./2013.
} 
mercantil. Nosso estudo de PPCS indica que Poulantzas, ainda que negando explicitamente, insere essa formulação pachukaniana no centro de seu conceito de Estado.

A forma jurídica, produzida pelas relações de troca que põem a igualdade e que, pela troca, vão conectar o produtor direto ao mecanismo coletivo de trabalho, determina a forma específica de todo Estado capitalista, acima dos sujeitos e garante de suas relações mercantis. A separação entre público e privado organiza toda a política: suas instituições, em especial o monopólio da violência legítima e a cena política, suas formas ideológicas próprias e as práticas das classes em luta. Nas três séries de determinações tal como estudadas por Poulantzas no MPC - estruturas, instituições e práticas - há sempre essa relação estrutural e lógica, que organiza a teoria do político no capitalismo.

\section{ESTADO E O DIREITO ENQUANTO INSTITUIÇÕES QUE MATERIALIZAM A CORRELAÇÃO DE FORÇAS}

Entretanto, esses avanços teóricos são parcialmente revistos pelo próprio autor em sua última obra. Em EPS, Poulantzas adere ao "socialismo democrático", uma corrente política, e anuncia revisões em sua teoria que justificariam semelhante tomada de posição. Antes de analisarmos as novidades teóricas que de fato Poulantzas introduz, façamos uma advertência. Bem vistas as coisas, EPS não rompe com boa parte das formulações contidas em PPCS, reproduzidas em parte nos primeiros capítulos e desenvolvidas nas mesmas bases. Isto é, há inconsistências e conflitos internos em EPS. Ao final cito duas que acho mais importante. De resto, não há nessa obra uma revisão global e ponto por ponto ${ }^{14}$. Mas deixemos de lado a problematização, necessária e por se fazer, da tese do "corte epistemológico" na obra poulantziana. Interessa-nos, aqui, supor o "corte" e comparar duas concepções distintas, para, com isso, iluminar possíveis inconsistências na interpretação coerente e geral que fazemos de Poulantzas - a mesma que, acreditamos, informam as pesquisas concretas realizadas no Brasil - e que partem fundamentalmente dos desenvolvimentos contidos em PPCS.

Bem, pretendendo se afastar do rótulo já desabonador - Estado, Poder e Socialismo é publicado em 1978 — de "estruturalista", Poulantzas afirma que o Estado, tal como o capital, é uma "relação social". Mas, como decorrência disto, afirma que a luta de classes atravessa os aparelhos de Estado. E que, teoricamente, as lutas detêm o primado sobre os aparelhos.

Sendo uma relação, o Estado é em cada momento uma condensação de uma relação de forças entre as classes em luta. A mudança é sutil. Em PPCS, já se afirmava a natureza relacional do poder. O passo que se dá é estender a condensação de forças, que antes estava no equilíbrio instável dos compromissos que sela a

\footnotetext{
${ }^{14}$ Para uma análise do direito nas três fases de Nicos Poulantzas, cf. Melo, Thiago Arcanjo Calheiros. O direito na obra de Nicos Poulantzas. Dissertação de mestrado. São Paulo: Universidade Presbiteriana Mackenzie, 2012.
} 
unidade do bloco no poder e de uma hegemonia, para os aparelhos de Estado - e destes para a função global que desempenha na macroestrutura capitalista. Pois, uma vez que a luta de classes os atravessam, Poulantzas abre a possibilidade de se pensar que o proletariado pode estar não só representado no interior dos aparelhos mas estar, numa conjuntura, em pé de igualdade ou em superioridade.

Antes, em PPCS, o crescimento da força dos dominados gerava uma crise no bloco no poder. Lembremo-nos que uma parte do aparelho de Estado poderia intervir para revolver a crise, como no bonapartismo. Agora, em EPS, sub-repticiamente, esse aparelho tem seu conteúdo determinado não pela estrutura social - ainda que fosse dinamizado pelas lutas -, senão pela classe que o ocupa ou que é mais forte na balança da correlação de forças. Poulantzas filia-se aqui ao "socialismo democrático" ou ao homólogo "eurocomunismo", e afirma na última página de EPS que, para evitar os riscos das experiências socialistas "reais", deveria o movimento operário e socialista “[... manter-se tranquilo e marchar direito sob os auspícios e a palmatória da democracia liberal avançada." ${ }^{15}$. Tudo isso sugere uma dissolução da perspectiva estrutural de antes.

Mas, antes de concluir por ela, cabe registrar uma primeira incoerência. Páginas antes em EPS, Poulantzas falava-nos da "ossatura material" do Estado, a forma específica que o constituí já como parte da divisão social (capitalista) do trabalho, em verdade desenvolvendo, com mais elementos, uma tese estrutural já contida em PPCS. Assim, supor que os aparelhos são atravessados pelas lutas de classes e que são, afinal, a condensação da relação de forças significa, pois, descurar ou mesmo descartar o papel que essa "ossatura material" específica exerce na organização propriamente política das classes dominantes e na desorganização das classes dominadas.

Os direitos sociais, por exemplo. São conquistas da luta operária. Mas a função ideológica que cumprem não decorre dessa origem. É certo que podem ajudar a classe operária a se organizar melhor, se politizar mais e a ganhar confiança na luta - que incide sobre a conjuntura das forças em presença, e não diretamente sobre as estruturas. Mas podem e o fazem tais direitos servir também à cooptação e à desmobilização, notadamente pela forma do próprio direito: individual, subjetivo vivido como parte do mercado. Quando ofendido, é ao poder judiciário, ao mérito e à ordem que cabe apelar, para que, por cima das classes e em defesa dos interesses gerais, restabeleça-se o direito. Ainda que fortemente influenciada pela luta das massas populares, a política social do Estado não serve à constituição delas enquanto "Partido", para usarmos uma expressão de Gramsci. Como de resto, a existência do Direito do Trabalho ou dos direitos sociais não milita contra a reprodução das relações capitalistas de produção.

\footnotetext{
${ }^{15}$ POUlantZaS, Nicos. Estado, poder e socialismo, op. cit., p. 271.
} 
É evidente que mais direitos e mais democracia interessam aos trabalhadores, à exata medida que a ditadura e as provações materiais não lhes interessam. Mas tão-somente por permitirem que os trabalhadores lutem, se organizem e ganhem consciência e coesão - talvez a luta por direitos seja o aspecto mais importante. Diferentemente da burguesia, que pode, no limite, prescindir da auto-organização já que se organiza através do Estado, o proletariado só pode contar com sua própria organização e deve se preparar para enfrentar o aparato de Estado e destruí-lo. E isso porque, em suma, a forma política burguesa que estrutura o aparato estatal não é funcional à transformação das relações capitalistas de produção, senão, ao contrário, serve à sua reprodução.

Engels afirma, no texto que se converteu em seu "testamento político", que nas democracias a partir de fins do século XIX a quebra da legalidade seria uma provável reação da burguesia, trazendo a luta para o terreno da guerra aberta ou "de movimento". Aos socialistas, segundo Engels, incumbiria superar o romantismo das barricadas e lutas guerrilheiras de rua, ante a consolidação histórica da política, dos exércitos e da democracia de massas, correspondente ao desenvolvimento industrial que se via. Mas a luta sob a legalidade não significa, em tal formulação, o fim da necessidade histórica da revolução e da destruição do aparato de Estado para a construção de uma nova divisão social do trabalho, ao contrário do que se interpretam as leituras eurocomunistas e socialistas-democráticas, como de resto no velho reformismo da II Internacional, que suprimiram a necessidade da revolução ${ }^{16}$.

A adesão de Poulantzas ao socialismo-democrático interdita essa compreensão. Abre o flanco à suposição de que uma virada na correlação de forças entre dominantes e dominados tornar-se-ia uma mudança no papel dos aparelhos de Estado, aliás, a ser aceita pelas classes dominantes sem que a democracia liberal avançada viesse a ser transtornada numa tal situação.

Impõe-se aqui, então, o registro de uma segunda incoerência. Em EPS, Poulantzas analisa a conjuntura contemporânea e identifica o surgimento do que chama de "estatismo autoritário": o reforço do executivo, do papel da tecnocracia em pôr contra tendências às crises do capital e um estreitamento das esferas da democracia e da cidadania. Ora, nessa conjuntura, a transição ao socialismo através e a partir dessa democracia soa ainda mais irreal ${ }^{17}$.

Qual a relação dessa fase teórica de Poulantzas com o pensamento jurídico de P. Stuchka? Para fazer essa comparação, é preciso voltar o foco para a teoria, deixando de lado a opção pela corrente socialistademocrática. E isso porque Stuchka defende a necessidade da revolução, que gera uma nova legalidade revolucionária, em conformidade com a ideologia da classe que toma o poder.

\footnotetext{
${ }^{16}$ ENGELS, Friedrich. "As lutas de classes na França de 1848 a 1850 - Introdução de F. Engels”. In: Marx, Karl. Karl Marx e Friedrich Engels - textos v. III. São Paulo: Edições Sociais, 1977, pp. 93-110.

$\overline{{ }^{17} \mathrm{MELO}}$, Thiago Arcanjo Calheiros. O direito na obra de Nicos Poulantzas, op. cit., pp. 142-3.
} 
O ponto de contato com a formulação poulantziana de $E P S$ reside mais no fundo. Em que pese Stuchka tratar da transição socialista e do Estado e do direito pós-revolução proletária, há uma correspondência entre, de um lado, sua concepção da forma jurídica, praticamente vazia e instrumental eis que apta a receber um conteúdo proletário, e, de outro, a concepção poulantziana de primado das lutas sobre os aparelhos, tidos como "condensação material" de uma relação de forças que lhe dá o conteúdo de classe. Stuchka limita o alcance da revolução ao controle dos aparelhos de Estado e da legalidade. Não põe em questão para a transição a uma nova sociabilidade a necessidade de transformação das próprias estruturas políticas.

É exatamente o mesmo que se passa com a concepção poulantziana acerca do primado das lutas sobre o Estado enquanto "condensação material" de uma relação de forças, que abstrai sua própria estrutura e que determina, enfim, seu conteúdo e sua função. Poulantzas retorna, assim, ao normativismo marxista.

Bem vistas as coisas, a adesão tardia de Poulantzas ao "socialismo democrático" encontra apoio em seus raciocínios normativistas que alimentam as críticas diretas que faz a Pachukanis nos textos que precedem e que são incorporados em $P P C S$, ainda que incoerentemente com a análise estrutural ali contida ${ }^{18}$. Pachukanis é acusado de economicista por derivar o direito das relações de produção ou, o que não muda as coisas, de "circulacionista", por derivar o direito da circulação mercantil. Não vê, Poulantzas, todavia, que embora o conteúdo da legislação e das instituições estatais possam variar conforme a dinâmica das classes, não escapam, todavia, aos limites estruturais do nível político do modo de produção capitalista, limites que ele próprio identifica quando analisa o Estado - a estrutura de igualdade que nivela, individualiza e isola os agentes e que corresponde ao despojamento dos produtores diretos face aos meios de produção e às relações de dependência pessoal.

Em outras palavras, adesão ao "socialismo democrático" não é outra coisa que uma consequência política permitida por uma incoerência ou imprecisão na teoria mesma, que leva Poulantzas a negar explicitamente a teoria de Pachukanis da forma jurídica e a aceitá-la implicitamente em seu conceito de Estado capitalista. Essa confusão se torna dramática em sua última obra. E uma revigorada ênfase na dinâmica relacional do poder e das instituições — dinâmica que o sistema estrutural de Poulantzas nunca negou —, responde pela expulsão política, no plano da estratégia dos dominados face ao Estado, das consequências lógicas da análise da estrutura desse Estado como funcional ao modo de produção capitalista.

\footnotetext{
${ }^{18}$ Barison, Thiago. Nicos Poulantzas e o direito, op. cit. Cf. MOTTA, Luiz Eduardo. "Direito, estado e poder: Poulantzas e o seu confronto com Kelsen”. Rev. Sociol. Polít., Curitiba, v. 19, n. 38, Feb.2011.
} 


\title{
CONSIDERAÇÕES FINAIS
}

Feito todo esse percurso, acredita-se estar suficientemente sugerida a importância de se reabrir o debate sobre o "corte epistemológico" supostamente havido entre as duas obras aqui comparadas e se avançar sobre uma reinterpretação global de Nicos Poulantzas a partir dos conceitos-chave, que envolvem o direito e as instituições do Estado capitalista e de uma crítica de sua última obra, cujas inconsistências são patentes.

O tratamento preciso e específico de estruturas e instituições com diferentes esferas de eficácia na totalidade social permite dar conta tanto do direito como forma jurídica, quanto da legalidade e das instituições estatais que materializam conteúdos dinamizados pelas práticas de classe no interior de tal estrutura. Assim, a superação dos traços normativistas de Poulantzas por esse trabalho de retificação crítica permite se extrair a concepção política mais coerente com o todo de sua teoria.

\section{NICOS POULANTZAS AND THE LAW: BETWEEN PACHUKANIS AND STUCHKA}

\begin{abstract}
:
This essay compares two texts of Nicos Poulantzas where the author sustains different conceptions of the capitalist state. The comparison depends on the thesis of two Marxist studiers of the juridical phenomena, Stuchka and Pachukanis. The book Political Power and Social Classes does a structural analysis of the State that puts it in relation to the conditions of reproduction of the capitalist mode of production, which corresponds to the formulation of Pachukanis on the legal form and the commodity form. In the book State, Power and Socialism, Poulantzas introduces changes that can bring him closer to the normativist Stuchka's theory, in which the state and the law are designed from the class power. The comparison throws light on possible inconsistencies in poulantzian theoretical edifice and on the paths to their critical rectification.
\end{abstract}

Keywords: Capitalist state; juridical form and commodity form; institutional materiality of the state and relationship of forces; normativist Marxism.

\section{BIBLIOGRAFIA}

AlthusSer, Louis. “A Querela do Humanismo I”. In: Revista Crítica Marxista. São Paulo: Editora Xamã, n. 9, 1999, pp.9-51.

BALIBAR, Étienne. “Elementos para una teoría del tránsito”. In: ALTHUSSER, Louis; 335.

Para Leer el Capital. $4^{a}$ ed. Trad. Marta Harnecker. Mexico: Siglo Ventiuno Editores, 1970, pp. $297-$

BARISON, Thiago. Nicos Poulantzas e o direito: um estudo de Poder político e classes sociais. Dissertação de mestrado. São Paulo: Faculdade de Direito/Universidade de São Paulo, 2010. 
BOITO JR., Armando. Estado, política e classes sociais - ensaios teóricos e históricos. São Paulo: Unesp, 2007, cap. 6, "Cena política e interesses de classe na sociedade capitalista: a análise de Marx", pp. 137-151.

CoDATO, Adriano. "Poulantzas, o Estado e a revolução. In: Revista Crítica Marxista. São Paulo, n. 27, 2008, pp. $65-85$

ENGELS, Friedrich. "As lutas de classes na França de 1848 a 1850 - Introdução de F. Engels”. In: MARX, Karl. Karl Marx e Friedrich Engels - textos v. III. São Paulo: Edições Sociais, 1977, pp. 93-1 10.

GramsCI, Antonio. Cadernos do Cárcere v. 3 - Maquiavel: notas sobre o Estado e a Política. Trad. Carlos Nelson Coutinho. Rio de Janeiro: Civilização Brasileira, 2000.

HANDAL, Jorge Shafik. El Poder, el Carácter y la Vía de la Revolución y la Unidad de la Izquierda El Salvador: 1981. Disponível em: "http:/ /www.marxists.org/espanol/handal/1981/001.htm", acesso em set./2013.

JESSOP, Bob. Nicos Poulantzas: Marxist Theory and Polítical Strategy. London: Macmillan, 1985.

LÊNIN, V. I., O Estado e a Revolução. São Paulo: Expressão Popular: 2007.

MARX, Karl. "O 18 Brumário de Luís Bonaparte”. In: Iasi, Mauro. (org.). A revolução antes da revolução II Karl Marx. São Paulo: Expressão Popular, 2008 (coleção “Assim lutam os povos”), pp. 199-337.

MASCARO, Alysson Leandro. Estado e forma política. São Paulo: Boitempo, 2013.

Melo, Thiago Arcanjo Calheiros. O direito na obra de Nicos Poulantzas. Dissertação de mestrado. São Paulo: Universidade Presbiteriana Mackenzie, 2012.

MilibAND, Raph. "Poulantzas and the Capitalist State".In: New Left Review, n. 82, 1973, pp. 83-92.

MоттA, Luiz Eduardo. "Direito, estado e poder: Poulantzas e o seu confronto com Kelsen". Rev. Sociol. Polít., Curitiba, v. 19, n. 38, fev./2011.

NAVES, Márcio Bilharinho. Marx: ciência e revolução. São Paulo: Quartier Latin, 2008.

PASUKANIS, E. B. Teoria geral do direito e o marxismo. Trad. Paulo Bessa. Rio de Janeiro: Renovar, 1989.

POUlAntZAS, Nicos. “The Capitalist State - Replyto Miliband and Laclau”. In: New Left Review, n. 96, 1976b, pp. 63-83. Fontes, 1977.

Poder político e classes sociais. Trad. Francisco Silva; Rev. Carlos R. F. Nogueira. São Paulo: Martins Estado, poder e socialismo. 4a ed. Trad. Rita Lima. São Paulo: Paz e Terra, 2000, (1ª ed., 1978).

SAES, Décio. “A questão da autonomia relativa do Estado em Poulantzas”. In: Revista Crítica Marxista. Rio de Janeiro: Xamã, n. 7, 1998a, pp. 46-66. 
Stuchk, P. I. "The Revolutionary Part Played by Law and the State - A General Doctrine of Law". In: Hazard, John N. (org.). Soviet Legal Philosophy. Cambridge: Harvard University Press, 1951, pp. 17-69.

Trabalho recebido aprovado em setembro de 2014. 